\title{
Níveis de energia líquida para suínos machos castrados em terminação
}

\author{
Net energy levels for finishing barrows
}

\author{
Liliane Maria Piano Gonçalves ${ }^{I}$ Charles Kiefer $^{I^{*}}$ Karina Márcia Ribeiro de Souza $^{\mathrm{I}}$ \\ Danilo Alves Marçal ${ }^{I}$ Rodrigo Caetano de Abreu ${ }^{I}$ Ariadne Maria Portilho Saturnino da Silva ${ }^{\mathrm{I}}$ \\ Stephan Alexander da Silva Alencar ${ }^{\mathrm{I}}$
}

RESUMO

Conduziu-se este estudo com o objetivo de avaliar níveis de energia líquida na dieta de suínos machos castrados em terminação. Foram utilizados 100 suínos, com peso inicial de $73,60 \pm 4,80 \mathrm{~kg}$, distribuídos em delineamento de blocos ao acaso, com cinco níveis de energia líquida (2.300, 2.425, 2.550, 2.675 e $2.800 \mathrm{kcal} \mathrm{kg}^{-1}$ de dieta), dez repetições e dois animais por unidade experimental. Os niveis de energia líquida foram obtidos através da inclusão crescente de óleo de soja em substituição ao caulim. Houve redução $(P<0,05)$ no consumo de ração diário, consumo de lisina e consumo de proteína bruta e melhora da conversão alimentar com o aumento dos níveis de energia líquida das dietas. O melhor nível de energia líquida para suínos machos castrados

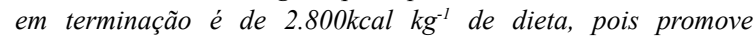
redução no consumo de ração diário $(P<0,05)$ e melhora a conversão alimentar $(P<0,05)$, sem alterar o ganho de peso e as características de carcaça.

Palavras-chave: carcaça, conteúdo energético, desempenho, nutrição.

\section{ABSTRACT}

This study was carried out to evaluated levels of net energy in the diet of finishing barrows. Were used 100 swines with an initial body weight of $73.60 \pm 4.80 \mathrm{~kg}$, distributed in a randomized block design, with five levels of net energy $(2,300 ; 2,425 ; 2,550$; 2,675 and 2,800kcal $\mathrm{kg}^{-1}$ of diet), ten replicates and two animals per experimental unit. The net energy levels were obtained by replacement of soybean oil to replace kaolin. There was a reduction in feed intake, of lysine and crude protein intake and improves feed conversion with increasing levels of net energy diets. The best level of net energy for finishing barrows is 2,800 $\mathrm{kcal} \mathrm{kg}^{-1}$ of diet as it foment reduction in feed intake and improves feed conversion without changing the weight gain and carcass characteristics.

Key words: carcass, energy content, performance, nutrition.

\section{INTRODUÇÃO}

A alimentação é o fator de maior custo na produção suinícola e a energia é o componente nutricional responsável pela maior parte deste custo (NOBLET, 1996). O conteúdo energético das rações é um dos componentes nutricionais mais relevantes para o desempenho de suínos na fase de terminação. Portanto, é importante caracterizar o conteúdo energético das dietas e buscar a eficiência na nutrição de suínos, aliando ganhos biológicos e econômicos.

Existem diferentes sistemas disponíveis para a caracterização da energia dietética, sendo os mais comuns a energia digestível e metabolizável (ROSTAGNO et al., 2007). Contudo são antigos e incompletos, já que descrevem parcialmente o aproveitamento da energia da dieta pelos suínos. Aliado a isso está o fato de que o constante melhoramento genético dos suínos leva ao aumento das exigências proteicas e energéticas dos animais. Com isso, tornase necessário reavaliar constantemente as exigências nutricionais e as necessidades energéticas dos suínos.

A energia líquida tem sido proposta como um sistema mais completo e que descreve de forma mais precisa o conteúdo energético real da dieta, quando comparado aos sistemas de energia digestível e metabolizável (NOBLET \& VAN MILGEN, 2004). A energia líquida permite uma estimativa mais acurada dos efeitos da dieta no desempenho dos suínos (MOEHN et al., 2005), pois considera as diferenças de metabolização dos nutrientes (NOBLET, 1996).

'Faculdade de Medicina Veterinária e Zootecnia, Universidade Federal de Mato Grosso do Sul (UFMS), 97070-900, Campo Grande, MS, Brasil. E-mail: charles.kiefer@ufms.br.*Autor para correspondência. 
As respostas de desempenho e características quantitativas e qualitativas de carcaça em função dos níveis energéticos das dietas são fundamentais para se estabelecer estratégias de alimentação adequadas para cada fase de produção. Todavia, há grande carência na literatura nacional das respostas e efeitos da formulação de dietas com base em energia líquida na produtividade dos suínos.

Diante disso, este estudo foi conduzido com o objetivo de avaliar os efeitos dos níveis de energia líquida na dieta de suínos, machos castrados em terminação, no desempenho e características quantitativas de carcaça.

\section{MATERIAL E MÉTODOS}

Foram utilizados 100 suínos, machos castrados de linhagem comercial (Duroc/Pietrain $\mathrm{x}$ Large White/Landrace), de alto potencial para deposição de proteína, com peso médio inicial de $73,60 \pm 4,80 \mathrm{~kg}$. Os animais foram distribuídos em delineamento experimental de blocos ao acaso, com cinco níveis de energia líquida $(2.300,2.425,2.550,2.675$ e $2.800 \mathrm{kcal}$ $\mathrm{kg}^{-1}$ de dieta), dez repetições e dois animais por unidade experimental. Para formação dos blocos, levou-se em consideração o peso inicial dos animais.

Os animais foram alojados em baias providas de comedouro semi-automático e bebedouros pendulares, em galpão de alvenaria, coberto por telhas cerâmicas. A temperatura e a umidade relativa do ar foram monitoradas diariamente às $8 \mathrm{~h}$ e $16 \mathrm{~h}$ durante o período experimental, por meio de um conjunto de termômetros de bulbo seco e bulbo úmido e de globo negro, instalados no centro do galpão. Os valores registrados foram convertidos no índice de temperatura de globo e umidade, que, segundo BUFFINGTON et al. (1981) caracteriza o ambiente térmico em que os animais foram mantidos.

As dietas experimentais (Tabela 1) eram isonutritivas e foram preparadas a base de milho e farelo de soja e suplementadas com aminoácidos, minerais e vitaminas. A formulação foi realizada para atender às exigências nutricionais propostas por ROSTAGNO et al. (2011) para suínos machos castrados de alto potencial genético e desempenho superior, dos 70 aos 100kg. A energia líquida das dietas experimentais foi calculada com base na composição média das matérias-primas, segundo ROSTAGNO et al. (2011), obtendo-se os diferentes níveis por meio da inclusão de óleo de soja em substituição ao caulim, mantendo-se o mesmo padrão de proteína ideal entre as dietas. As rações e a água foram fornecidas à vontade aos animais durante todo o período experimental, que teve duração de 30 dias.
Os animais foram pesados no início e no final do experimento, bem como o consumo total de ração, com o qual foram calculados os consumos de ração diário, de proteína, de lisina e de energia líquida, ganho de peso diário e a conversão alimentar de cada unidade experimental.

Ao final do período experimental, os animais foram pesados e transportados para frigorífico comercial, onde permaneceram em baia de descanso, com acesso à água e sob jejum de sólidos por 10 horas.

Por ocasião do abate, os suínos foram insensibilizados pelo método elétrico (eletronarcose) e, posteriormente, sangrados, escaldados e eviscerados, segundo normas do RIISPOA (BRASIL, 1952).

Ao final da linha de abate, as cabeças foram retiradas, as carcaças foram divididas longitudinalmente e as meias-carcaças pesadas individualmente. Foi determinado o comprimento das carcaças de acordo com o Método Brasileiro de Classificação de Carcaça (ABCS, 1973). Na meia-carcaça esquerda, foi realizado corte no ponto P2 (correspondente à projeção perpendicular da última costela a quatro $\mathrm{cm}$ da coluna vertebral), para a exposição do músculo Longissimus dorsi e da camada de toucinho, para medição da profundidade do músculo e da espessura de toucinho, por meio de paquímetro digital, na carcaça quente.

O percentual de carne, a quantidade de carne e o índice de bonificação das carcaças foram determinados com os valores de peso de carcaça quente, espessura de toucinho e profundidade de músculo, por meio de equações propostas por BRIDI \& SILVA (2007), em que: percentual de carne magra $(\%)=60-($ espessura de toucinho $\times 0,58)+$ (profundidade de músculo x 0,1); quantidade de carne magra $(\mathrm{kg})=($ peso de carcaça quente $\mathrm{x}$ percentual de carne magra) / 100; índice de bonificação $=23,6$ $+(0,286 \times$ peso de carcaça quente $)+$ (percentual de carne magra).

As variáveis de desempenho (ganho de peso, consumos de ração, de proteína, lisina e energia e a conversão alimentar), as características quantitativas de carcaça (peso e comprimento de carcaça quente, espessura de toucinho, profundidade de músculo, percentual e quantidade de carne na carcaça) e o índice de bonificação obtidos foram submetidas à análise de variância pelo procedimento do modelo linear geral, do programa estatístico SAS, versão 9.0 , a $5 \%$ de significância. O peso inicial foi utilizado como co-variável no modelo estatístico. Os dados foram submetidos à análise de regressão 
Tabela 1 - Composição centesimal e nutricional das dietas experimentais.

\begin{tabular}{|c|c|c|c|c|c|}
\hline Ingrediente & 2.300 & 2.425 & 2.550 & 2.675 & 2.800 \\
\hline Milho & 70,15 & 70,15 & 70,15 & 70,15 & 70,15 \\
\hline Farelo de soja $(45 \%)$ & 20,44 & 20,44 & 20,44 & 20,44 & 20,44 \\
\hline Óleo de soja & 0,000 & 1,697 & 3,394 & 5,091 & 6,800 \\
\hline Inerte (caulim) & 6,900 & 5,203 & 3,506 & 1,809 & 0,100 \\
\hline Fosfato bicálcico & 0,832 & 0,832 & 0,832 & 8,32 & 8,32 \\
\hline Calcário calcítico & 0,445 & 0,445 & 0,445 & 0,445 & 0,445 \\
\hline Suplemento Vit.+Min. ${ }^{1}$ & 0,100 & 0,100 & 0,100 & 0,100 & 0,100 \\
\hline Sal comum & 0,305 & 0,305 & 0,305 & 0,305 & 0,305 \\
\hline L-Lisina $\mathrm{HCl}$ & 0,451 & 0,451 & 0,451 & 0,451 & 0,451 \\
\hline DL-Metionina & 0,159 & 0,159 & 0,159 & 0,159 & 0,159 \\
\hline L-Treonina & 0,177 & 0,177 & 0,177 & 0,177 & 0,177 \\
\hline \multirow[t]{2}{*}{ L-Triptofano } & 0,037 & 0,037 & 0,037 & 0,037 & 0,037 \\
\hline & & 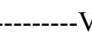 & hutricionai & $\operatorname{lados}^{2}-$ & \\
\hline Energia líquida ( $\mathrm{kcal} \mathrm{kg}^{-1}$ ) & 2.300 & 2.425 & 2.550 & 2.675 & 2.800 \\
\hline Energia metabolizável $\left(\mathrm{kcal} \mathrm{kg}^{-1}\right)$ & 3.045 & 3.186 & 3.327 & 3.468 & 3.608 \\
\hline Proteína bruta $(\%)$ & 16,00 & 16,00 & 16,00 & 16,00 & 16,00 \\
\hline Lisina digestível (\%) & 1,000 & 1,000 & 1,000 & 1,000 & 1,000 \\
\hline Met+Cist digestível (\%) & 0,617 & 0,617 & 0,617 & 0,617 & 0,617 \\
\hline Treonina digestível (\%) & 0,667 & 0,667 & 0,667 & 0,667 & 0,667 \\
\hline Triptofano digestível (\%) & 0,187 & 0,187 & 0,187 & 0,187 & 0,187 \\
\hline Valina digestível (\%) & 0,638 & 0,638 & 0,638 & 0,638 & 0,638 \\
\hline Arginina digestível (\%) & 0,259 & 0,259 & 0,259 & 0,259 & 0,259 \\
\hline Histidina digestível (\%) & 0,164 & 0,164 & 0,164 & 0,164 & 0,164 \\
\hline Leucina digestível (\%) & 0,669 & 0,669 & 0,669 & 0,669 & 0,669 \\
\hline Fenil+Tir digestível (\%) & 0,432 & 0,432 & 0,432 & 0,432 & 0,432 \\
\hline Cálcio (\%) & 0,484 & 0,484 & 0,484 & 0,484 & 0,484 \\
\hline Fósforo disponível (\%) & 0,248 & 0,248 & 0,248 & 0,248 & 0,248 \\
\hline Sódio (\%) & 0,160 & 0,160 & 0,160 & 0,160 & 0,160 \\
\hline
\end{tabular}

1- Conteúdo por quilograma do produto: Vit. A - 1.250.000UI; Vit. $\mathrm{D}_{3}-250.000 \mathrm{UI}$; Vit. E - 6.250UI; Vit. $\mathrm{K}_{3}-\mathrm{750}_{\mathrm{mg}}$; Vit. B $\mathrm{B}_{1}-375 \mathrm{mg}$; Vit. $\mathrm{B}_{2}-1.000 \mathrm{mg}$; Vit. $\mathrm{B}_{6}-375 \mathrm{mg}$; Vit. $\mathrm{B}_{12}-4.500 \mathrm{mcg}$; niacina - 4.500mg; Ácido pantotênico - 2.300mg; Ácido fólico - 125mg; ferro - 25g; cobre $-3.750 \mathrm{mg}$; manganês - $12.5 \mathrm{~g}$; zinco $-31.25 \mathrm{~g}$; iodo $-250 \mathrm{mg}$; selênio - $75 \mathrm{mg}$ e excipiente q.s.p. - $1000 \mathrm{~g}$.

${ }^{2-}$ Valores calculados com base na composição nutricional das matérias-primas, conforme ROSTAGNO et al. ( 2011).

linear e/ou quadrática em função do melhor ajuste do modelo às variáveis.

\section{RESULTADOS E DISCUSSÃo}

Durante o período experimental, os valores médios de temperatura do ar, umidade relativa do ar, temperatura de globo negro e índice de temperatura de globo e umidade foram de $24,4 \pm 4,6^{\circ} \mathrm{C}, 65,6 \pm 18,4 \%, 27,1 \pm 3,9^{\circ} \mathrm{C}$ e $75,1 \pm 4,8$, respectivamente. A temperatura média do ambiente observada durante o período experimental pode ser considerada termoneutra para suínos em fase de terminação, uma vez que está dentro da faixa de temperaturas de 18 a $26^{\circ} \mathrm{C}$, ideal para suínos nesta categoria. $\mathrm{O}$ índice de temperatura de globo e umidade registrado apresentou valor acima do limite superior de conforto térmico de 72, para suínos em terminação. Os níveis de energia líquida das dietas experimentais não influenciaram $(\mathrm{P}>0,05)$ o peso final dos animais (Tabela 2). Houve redução linear $(\mathrm{P}<0,01)$ no consumo de ração diário dos animais em razão do aumento da energia líquida das dietas. Essa resposta justifica-se pelo fato de que os suínos podem alterar o consumo de ração, buscando ajustálo aos níveis de energia da dieta. Em geral, quanto mais elevado o nível de energia da dieta, menor será o consumo voluntário dos animais. Portanto, a utilização de dietas com alta densidade energética na fase de terminação torna o consumo voluntário dos animais reduzido e tem sido associado, também, à melhora na eficiência alimentar.

Ciência Rural, v.45, n.3, mar, 2015. 
Tabela 2 - Desempenho de suínos machos castrados em terminação, alimentados com dietas contendo diferentes níveis de energia líquida.

\begin{tabular}{|c|c|c|c|c|c|c|c|}
\hline \multirow{2}{*}{ Variáveis } & \multicolumn{7}{|c|}{ 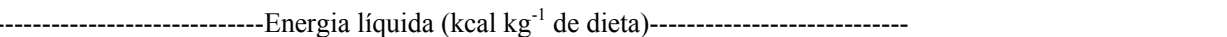 } \\
\hline & 2.300 & 2.425 & 2.550 & 2.675 & 2.800 & & \\
\hline Peso inicial, kg & 73,56 & 73,57 & 73,85 & 73,49 & 73,66 & - & - \\
\hline Peso final, $\mathrm{kg}$ & 97,53 & 95,95 & 96,99 & 99,03 & 97,03 & 0,193 & 3,09 \\
\hline $\mathrm{CRD}, \mathrm{kg}^{*}$ & 2,42 & 2,25 & 2,15 & 2,20 & 2,09 & 0,012 & 9,52 \\
\hline CLD, $\mathrm{g}^{*}$ & 24,25 & 22,46 & 21,48 & 22,01 & 20,90 & 0,012 & 9,52 \\
\hline CPD, $\mathrm{g}^{*}$ & 387,95 & 359,40 & 343,66 & 352,24 & 334,41 & 0,012 & 9,52 \\
\hline CELD, kcal & 5576,8 & 5447,2 & 5477,1 & 5889,0 & 5852,1 & 0,219 & 9,70 \\
\hline GPD, kg & 0,81 & 0,76 & 0,79 & 0,87 & 0,79 & 0,195 & 12,85 \\
\hline $\mathrm{CA}, \mathrm{kg} \mathrm{kg}^{-1} *$ & 3,04 & 2,98 & 2,75 & 2,56 & 2,64 & 0,002 & 10,59 \\
\hline
\end{tabular}

CRD (consumo de ração diário), CLD (consumo de lisina diário), CPD (consumo de proteína diário), CELD (consumo de energia líquida diário), GPD (ganho de peso diário), CA (conversão alimentar).

*Efeito linear $(\mathrm{P}<0,05)$; Consumo de ração diário: $\mathrm{Y}=3,678-0,000 \mathrm{x} ; \mathrm{r}^{2}=0,78$; Consumo de lisina diário: $\mathrm{Y}=36,78-0,005 \mathrm{x} ; \mathrm{r}^{2}=0,78 ;$ Consumo de proteína bruta diário: $\mathrm{Y}=588,6-0,091 \mathrm{x} ; \mathrm{r}^{2}=0,78$; Conversão alimentar: $\mathrm{Y}=5,277-0,001 \mathrm{x} ; \mathrm{r}^{2}=0,85$.

Este resultado corrobora os obtidos por REZENDE et al. (2006), utilizando quatro níveis de energia metabolizável $(3.100,3.230,3.370$ e $3.500 \mathrm{kcal} \mathrm{kg}^{-1}$ de ração), mantendo a relação energia metabolizável:lisina digestível constante. Também KIL et al. (2011) e QUINIOU \& NOBLET (2012), utilizando $3.100,3.230,3.370$ e $3.500 \mathrm{kcal}$ de energia líquida $\mathrm{kg}^{-1}$ de dieta, observaram redução linear do consumo de ração diário de suínos em fase de terminação, em função do aumento da densidade energética da dieta.

O consumo de lisina diminuiu linearmente $(\mathrm{P}<0,01)$ em relação ao aumento do nível energético das dietas. Essa resposta está de acordo com a resposta observada na redução no consumo de ração diário. A redução na ingestão de lisina não prejudicou o ganho de peso diário e as características de carcaça dos suínos, possivelmente devido à melhor digestibilidade e metabolização de lisina, pois o teor de energia líquida das dietas supriu a necessidade energética para mantença dos suínos e para excreção de produtos nitrogenados.

O consumo de proteína bruta diminuiu linearmente $(\mathrm{P}<0,01)$ em relação ao aumento do nível energético das dietas, fato que corrobora o observado no consumo de lisina. Mesmo com a variação nas relações energia:proteína das dietas experimentais, a redução na ingestão de proteína não afetou o ganho de peso diário e as características de carcaça dos suínos. Esse resultado pode ser considerado positivo, pois demonstra que não foi necessário suplementar as dietas com proteína, o que elevaria o custo das formulações.

Não houve efeito $(\mathrm{P}>0,05)$ dos níveis de energia sobre o consumo de energia líquida diário dos suínos. Essa resposta pode ser explicada pelo ajuste no consumo voluntário de alimento para $o$ atendimento da exigência energética, em que, segundo REZENDE et al. (2006), os animais compensam a baixa densidade energética da dieta, aumentando a ingestão diária de alimento, até que a demanda energética seja atingida. Resultado contrário foi observado por pesquisadores como YI et al. (2010), que avaliaram níveis de 2.410; 2.450; $2.490 ; 2.530$ e $2.570 \mathrm{kcal} \mathrm{kg}^{-1}$; KIL et al. (2011), que estudaram níveis de $2.056 ; 2.206$ e $2.318 \mathrm{kcal} \mathrm{kg}^{-1}$; e QUINIOU \& NOBLET (2012), que testaram níveis de $1.935,2.078,2.221,2.365,2.508$ e $2.651 \mathrm{kcal}$ $\mathrm{kg}^{-1}$ e observaram aumento no consumo de energia líquida de acordo com o aumento dos níveis de energia líquida da dieta.

Os níveis de energia líquida nas dietas experimentais não influenciaram $(\mathrm{P}>0,05)$ o ganho de peso diário dos suínos, mesmo com as variações significativas observadas para o consumo de ração e consumos de lisina e proteína entre os tratamentos experimentais. Resultados similares foram reportados por REZENDE et al. (2006), que também não observaram variação no ganho de peso diário de suínos em terminação em função do aumento dos níveis (3.100, 3.230, 3.370 e 3.500) de energia metabolizável das dietas. Por outro lado, QUINIOU \& NOBLET (2012) observaram aumento no ganho de peso diário de machos castrados em crescimento e terminação, com o aumento da concentração (1.935, $2.078,2.221,2.365,2.508$, e $2.651 \mathrm{kcal}_{\mathrm{kg}^{-1}}$ ) de energia líquida das dietas.

A conversão alimentar melhorou linearmente $(\mathrm{P}<0,01)$ em função do aumento da concentração de energia líquida das dietas. Essa resposta pode estar associada aos efeitos positivos 
do óleo, utilizado como fonte energética nas dietas, sobre a digestibilidade dos nutrientes e também na possível melhora na relação energia: proteína das dietas (SILVA et al., 1998). Existem evidências de que a suplementação de óleo nas dietas pode reduzir a velocidade do trânsito da digesta, o que possibilitaria maior tempo para a digestão e absorção dos nutrientes, melhorando a conversão alimentar (ADEOLA \& ORBAN, 1995).

Melhora na conversão alimentar em função do aumento dos níveis de energia da dieta também foi observada por PAIANO et al. (2008) e por YI et al. (2010), estudando, respectivamente, cinco $\left(2.410 ; 2.450 ; 2.490 ; 2.530\right.$ ou $\left.2.570 \mathrm{kcal} \mathrm{kg}^{-1}\right)$ e quatro $\left(2.250,2.300,2.400\right.$ e $\left.2.450 \mathrm{kcal} \mathrm{kg}^{-1}\right)$ níveis de energia líquida nas dietas.

A redução do esvaziamento gástrico seria provocada pelo efeito inibitório que os lipídios exercem sobre este esvaziamento, principalmente, os lipídios com cadeias formadas por 12 a 18 carbonos, presentes em grande quantidade nos óleos e gorduras. Este efeito parece ser mediado pela ação da colecistocinina, liberada pela mucosa intestinal, em resposta à presença de lipídios na dieta (DONZELE et al., 1998). Essas respostas fisiológicas podem melhorar a eficiência de utilização dos nutrientes das dietas contendo maior nível de lipídios, conforme resposta verificada no presente estudo.

Os níveis de energia líquida não influenciaram $(\mathrm{P}>0,05)$ o peso e o comprimento de carcaça dos suínos (Tabela 3). Esses resultados sugerem que as dietas experimentais forneceram o aporte nutricional necessário para que os animais expressassem seu potencial produtivo. Resultados semelhantes foram obtidos por MOURA et al. (2011), para peso de carcaça quente e rendimento de carcaça, e por PAIANO et al. (2008) para peso, rendimento e comprimento de carcaça quente. No entanto, QUINIOU \& NOBLET (2012) observaram aumento no rendimento de carcaça de machos castrados, utilizando níveis de 1.935, 2.078, 2.221, 2.365, 2.508 e $2.651 \mathrm{kcal}$ de energia líquida $\mathrm{kg}^{-1}$ de dieta.

A profundidade de músculo e a espessura de toucinho também não foram influenciadas $(\mathrm{P}>0,05)$ pelos níveis de energia líquida. Essa resposta corrobora a redução no consumo de ração diário, indicando que os animais reduziram o consumo de ração para regular a ingestão de energia e, com isso, não houve aumento na espessura de toucinho. Resultados similares foram observados por MOURA et al. (2011) para profundidade de músculo e por De La LLATA et al. (2001) e REZENDE et al. (2006) para espessura de toucinho.

$\mathrm{O}$ percentual de carne magra e a quantidade de carne magra nas carcaças não foram influenciados $(\mathrm{P}>0,05)$ pelos níveis de energia líquida. Esses resultados, semelhantes aos obtidos por REZENDE et al. (2006), PAIANO et al. (2008) e QUINIOU \& NOBLET (2012), confirmam a capacidade dos suínos em ajustar a sua ingestão de alimentos, mesmo com ampla variação de concentrações de energia líquida, o que resulta em carcaças com o mesmo padrão de deposição de proteína.

O índice de bonificação, fator que tem sido utilizado como estratégia comercial para incentivar a produção de carcaças com maior percentual de proteína e menor de gordura depositada, não foi influenciado pelos níveis de energia líquida. Esse resultado, relacionado às respostas obtidas no percentual e quantidade de carne magra das carcaças, indica que a diferença energética entre as dietas não afetou a qualidade e o valor comercial das carcaças.

Tabela 3 - Características de carcaça de suínos machos castrados em terminação, alimentados com dietas contendo diferentes níveis de energia líquida.

\begin{tabular}{|c|c|c|c|c|c|c|c|}
\hline \multirow{2}{*}{ Variáveis } & \multicolumn{5}{|c|}{ Energia líquida ( $\mathrm{kcal} \mathrm{kg}^{-1}$ de dieta)--.-- } & \multirow{2}{*}{ Valor P } & \multirow{2}{*}{$\mathrm{CV}, \%$} \\
\hline & 2.300 & 2.425 & 2.550 & 2.675 & 2.800 & & \\
\hline PCQ, kg & 73,18 & 72,20 & 71,37 & 73,24 & 71,52 & 0,703 & 5,46 \\
\hline $\mathrm{CC}, \mathrm{cm}$ & 92,52 & 93,15 & 92,44 & 92,30 & 92,50 & 0,870 & 3,15 \\
\hline PM, mm & 83,79 & 79,32 & 81,40 & 75,34 & 84,60 & 0,138 & 11,73 \\
\hline $\mathrm{ET}, \mathrm{mm}$ & 13,09 & 12,85 & 13,32 & 14,77 & 13,92 & 0,177 & 16,68 \\
\hline Carne magra, $\%$ & 60,79 & 60,48 & 60,41 & 58,97 & 60,39 & 0,158 & 2,88 \\
\hline Carne magra, $\mathrm{kg}$ & 44,47 & 43,65 & 43,13 & 43,21 & 43,19 & 0,781 & 6,80 \\
\hline Índice de bonificação & 105,3 & 104,7 & 104,4 & 103,5 & 104,4 & 0,484 & 2,21 \\
\hline
\end{tabular}

PCQ (peso de carcaça quente), CC (comprimento de carcaça), PM (profundidade de músculo), ET (espessura de toucinho). 


\section{CONCLUSÃO}

Dentre os níveis estudados, o melhor nível de energia líquida para suínos machos castrados em terminação é de $2.800 \mathrm{kcal} \mathrm{kg}^{-1}$ de dieta, pois promove redução no consumo de ração diário e melhora a conversão alimentar, sem alterar o ganho de peso e as características de carcaça.

\section{COMITÊ DE ÉTICA E BIOSSEGURANÇA}

Projeto aprovado pela comissão de ética no uso de animais, sob protocolo nº429/2012 - Universidade Federal de Mato Grosso do Sul (UFMS).

\section{REFERÊNCIAS}

ABCS (ASSOCIAÇÃO BRASILEIRA DE CRIADORES DE SUÍNOS). Método brasileiro de classificação de carcaças. Estrela: ABCS, 1973. 17p

ADEOLA, O.; ORBAN, J.I. Chemical composition and nutrient digestibility of pearl millet (Pennisetum glaucum) fed to growing pigs. Journal of Cereal Science, v.22, p.177-184, 1995. Disponível em: <http://www.sciencedirect.com/science/ article/pii/0733521095900489>. Acesso em: 27 nov. 2013. doi:10.1016/0733-5210(95)90048-9.

BRASIL. Ministério da Agricultura, Pecuária e Abastecimento. Regulamento da Inspeção Industrial e Sanitária de Produtos de Origem Animal (RIISPOA). Brasília, 1952. 154p.

BRIDI, A.M.; SILVA, C.A. Métodos de avaliação da carcaça e da carne suína. Londrina: Midiograf, 2007. 97p.

BUFFINGTON, D.E. et al. Black globehumidity index (BGHI) as comfort equation for dairy cows. Transaction of the American Society of Agricultural Engineers, v.24, p.711-714, 1981. Disponível em: $<$ http://www.elibrary.asabe.org/abstract.asp?aid=34325\&t=2\&redir $=\&$ redirType $=>$. Acesso em: 20 nov. 2013. doi: 10.13031/2013.34325.

DE LA LLATA, M. et al. Effects of dietary fat on growth performance and carcass characteristics of growing-finishing pigs reared in a commercial environment. Journal of Animal Science, v.79, n.10, p.2643-2650, 2001. Disponível em: <http:// www.journalofanimalscience.org/content/79/10/2643.full $\mathrm{pdf}+\mathrm{html}$ ? sid=f1075de6-f71b-4090-9c3e-564b87624481>. Acesso em: 20 nov. 2013

DONZELE, J.L. et al. Digestibilidade e metabolizabilidade da energia de rações com diferentes níveis de óleo de soja para suínos. Revista Brasileira de Zootecnia, v.27, p.922-927, 1998. Disponível em: <http://www.revistasbz.org.br/scripts/revista/sbzl/ Artigos/2210.pdf $>$. Acesso em: 10 nov. 2013.

KIL, D.Y. et al. Net energy of soybean oil and choice white grease in diets fed to growing and finishing pigs. Journal of Animal Science, v.89, p.448-459, 2011. Disponível em: <http://www. journalofanimalscience.org/content/89/2/448.long $>$. Acesso em: 20 nov. 2013. doi: $10.2527 /$ jas.2010-3233.
MOEHN, S. et al. Using net energy for diet formulation: potential for the canadian pig industry. Advances in Pork Production, v.16, 119p, 2005

MOURA, M.S. et al. Níveis de energia líquida e ractopamina para leitoas em terminação sob conforto térmico. Revista Brasileira de Zootecnia, v.40, n.9, p.1968-1974, 2011. Disponível em: <http:// www. scielo.br/pdf/rbz/v40n9/a18v40n9.pdf>. Acesso em: 08 nov. 2013. doi:10.1590/S1516-35982011000900018.

NOBLET, J. Net energy for growth in pigs: application to low protein, amino acid supplemented diets. In: PORK INDUSTRY CONFERENCE, 1996, Urbana. Proceedings... Urbana: University of Illinois, 1996. p.15-25.

NOBLET, J.; VAN MILGEN, J. Energy value of pig feeds: Effect of pig body weight and energy evaluation system. Journal of Animal Science, v.82, p.229-238, 2004. Disponível em: <http:// www.journalofanimalscience.org/content/82/13_suppl/E229.full. pdf + html $>$. Acesso em: 08 nov. 2013.

PAIANO, D. et al. Relações treonina:lisina digestíveis e níveis de energia líquida para suínos em crescimento e terminação. Revista Brasileira de Zootecnia, v.37, p.2147-2156, 2008. Disponível em: <http://www.scielo.br/pdf/rbz/v37n12/11.pdf $>$. Acesso em: 08 nov. 2013. doi:10.1590/S1516-35982008001200011.

QUINIOU, N.; NOBLET, J. Effect of the dietary net energy concentration on feed intake and performance of growing-finishing pigs housed individually. Journal of Animal Science, v.90, p.43624372, 2012. Disponível em: $<\mathrm{http}$ ://www.journalofanimalscience. org/content/90/12/4362.full.pdf + html $>$. Acesso em: 08 nov. 2013. doi: $10.2527 /$ jas.2011-4004

REZENDE, W.O. et al. Níveis de energia metabolizável mantendo a relação lisina digestível:caloria em rações para suínos machos castrados em terminação. Revista Brasileira de Zootecnia, v.35, p.1101-1106, 2006. Disponível em: <http://www.scielo.br/pdf/ rbz/v35n3s0/30723.pdf>. Acesso em: 08 nov. 2013. doi: 10.1590/ S1516-35982006000400022.

ROSTAGNO, H.S. et al. Avanços metodológicos na avaliação de alimentos e de exigências nutricionais para aves e suínos. Revista Brasileira de Zootecnia, v.36, supl. esp., p.295-304, 2007. Disponível em: <http://www.scielo.br/pdf/rbz/v36s0/27.pdf $>$. Acesso em: 08 nov. 2013. doi: 10.1590/S1516-35982007001000027.

ROSTAGNO, H.S. et al. Tabelas brasileiras para aves e suínos: composição de alimentos e exigências nutricionais. 3.ed. Viçosa: UFV, 2011. 252p.

SILVA, F.C.O. et al. Níveis de energia digestível para suínos machos inteiros dos 60 aos $100 \mathrm{~kg}$. Revista Brasileira de Zootecnia, v.27, n.5, p.959-964, 1998. Disponível em: <http:// www. revistasbz.org.br/scripts/revista/sbz1/Artigos/2209.pdf>. Acesso em: 16 nov. 2013.

YI, X.W. et al. Influence of dietary net energy content on performance of growing pigs fed low crude protein diets supplemented with crystalline amino acids. Journal of Swine Health and Production, v.18, p.294-300, 2010. Disponível em: $<$ http://www.aasv.org/shap/issues/v18n6/v18n6p294.pdf $>$. Acesso em: 08 nov. 2013 